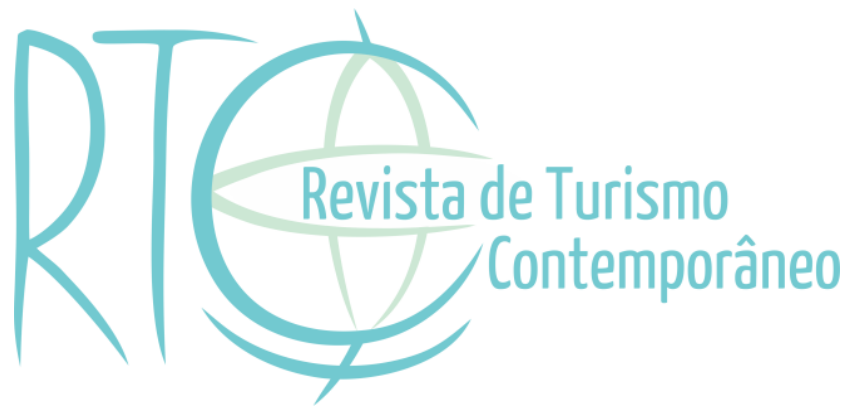

\title{
Análise da distribuição espacial e qualificação da oferta de hospedagem em Anápolis (Goiás/Brasil)
}

\section{Analysis of spatial distribution and qualification of the hosting offer in Anápolis (Goiás/Brazil)}

\section{Rangel Gomes Godinho}

Professor efetivo do Instituto Federal de Educação, Ciência e Tecnologia - IFG, Anápolis/GO, Brasil

E-mail: rangel.godinho@ifg.edu.br

\section{Maria Eduarda Gomes Pereira}

Graduanda em Técnico Integrado em Química pelo Instituto Federal de Educação, Ciência e Tecnologia de Goiás - IFG, Anápolis/GO, Brasil

E-mail: mariaeduarda200gp@gmail.com

\section{Luiz Gustavo Costa da Vitória Cotrim}

Graduando em Técnico Integrado em Química pelo Instituto Federal de Educação, Ciência e Tecnologia de Goiás - IFG, Anápolis/GO, Brasil

E-mail: luizgustavocosta0908@gmail.com 


\section{RESUMO}

Anápolis constitui-se como centro de crescente fluxo de mercadorias, pessoas e informações, tendo potencialidade para promover elementos locais como atrativos turísticos, o que implica investimento na oferta turística. O presente artigo tem como principal objetivo a análise da distribuição espacial e da qualificação da oferta de hospedagem de Anápolis (Goiás). Desse modo, apresenta a cartografia da oferta de hospedagem de Anápolis, contemplando a identificação dos objetos técnicos que compõem os meios de hospedagem e a participação das diferentes categorias na oferta de hospedagem. Para isso, realizou-se levantamento bibliográfico; levantamento de bases cartográficas; compilação de dados sobre a infraestrutura de hospedagem; georreferenciamento da hospedagem; elaboração, análise e interpretação de mapas temáticos com subsídio do software ArcGIS 10.2.2. Identificou-se que Anápolis conta com 27 meios de hospedagem, que se dividem em três categorias: Hotéis, Pousadas e Flat/Apart-hotel. Os hotéis se sobressaem quanto ao número de estabelecimentos e na oferta de leitos, seguidos das pousadas e do flat/Apart-hotel. Os estabelecimentos, em sua maioria, são de baixa qualificação, sendo $81 \%$ deles estão classificados com uma ou duas estrelas. Os estabelecimentos concentram-se na área central da cidade e sua dispersão acompanha a principal avenida de Anápolis (Avenida Brasil). Há um número maior de estabelecimentos que ofertam entre 16 e 79 vagas de leitos; somente a categoria dos hotéis apresenta disponibilidade acima de 113 leitos. Conclui-se que há necessidade de um planejamento turístico em Anápolis atento à oferta de hospedagem da cidade, no sentido de promover a diversidade de categorias de estabelecimentos e qualificação dos empreendimentos.

Palavras-chave: Cartografia Turística. Oferta Turística. Hospedagem. Anápolis.

\section{ABSTRACT}

Anápolis is a center of increasing flow of goods, people and information, with the potential to value local elements as tourist attractions, which implies investment in the tourist offer. The main objective of this article is to analyze the spatial distribution and the qualification of the accommodation offer in Anápolis (Goiás). In this way, it presents the cartography of the accommodation offer in Anápolis, contemplating the identification of the technical objects that make up the means of accommodation and the participation of the different categories in the accommodation offer. For this, a bibliographic survey was carried out; survey of cartographic bases; Compilation of data in the hosting infrastructure; georeferencing of accommodation; elaboration, analysis and interpretation of thematic maps supported by ArcGIS 10.2.2. It was identified that Anápolis has 27 means of accommodation, which are divided into three categories: Hotels, Inns and Flat / Apart-hotel. The hotels predominate in terms of the number of establishments and the number of beds, followed by the inns and the flat/apart-hotel. Most establishments are of low qualification. The establishments are concentrated in the central region of the city and its dispersion follows the main avenue of the city. The number of establishments offering between 16 and 79 beds is greater; only the category of hotels has availability over 113 beds. It is concluded that there is a need for tourism planning attentive to the city's accommodation offer, in order to promote the diversity of categories of establishments and the qualification of the enterprises.

Keywords: Tourist Cartography. Tourist Offer. Accommodation. Anápolis. 


\section{INTRODUÇÃO}

A cidade de Anápolis, fundada em 1907, tem sua origem na movimentação de tropeiros que abasteciam as províncias de Goiás, onde a mineração do ouro era intensa durante o século XVIII. Os cursos hídricos, pertencentes à área que viria a ser Anápolis, foram importantes referencias de orientação e também locais de descanso durante o ciclo do ouro. Fato que ao longo do tempo favoreceu a instalação de comunidades nessa região que posteriormente levou a formação de Anápolis. Essa referência histórica permite refletir sobre a posição estratégica de Anápolis no cenário regional, que perpetua até a atualidade e se potencializa pela presença em seu território da estação aduaneira do interior (EADI), denominada de Porto Seco, e do Distrito Agroindustrial (DAIA), onde está instalado o Polo Farmacêutico de Genéricos que tem se consolidado como o maior da América Latina. Em Anápolis também se situam três rodovias federais que se interligam (as Br's 060, 153 e 414) e as ferrovias Centro-Atlântica e Norte-Sul, importantes instrumentos de integração econômica nacional, pois interligam o Porto Seco à outros portos e estradas brasileiras, como a estrada de ferro Carajás e os portos de Santos (SP) e Vitória (ES) (Prefeitura de Anápolis, 2020).

Godinho, Ferreira e Mesquita (2006) destacam que o DAIA e o Porto Seco trouxeram para Anápolis, e para o Estado de Goiás, grande crescimento econômico, pois promoveram a atração de investimentos ao polo agroindustrial, intensificando as relações comerciais a nível nacional e internacional, além de gerar empregos para a população local, especialmente postos de trabalho que exigem mão de obra qualificada. É relevante destacar que o crescimento econômico veio acompanhado de desgaste ambiental (desmatamento para a construção deste grande complexo aduaneiro).

Outro fator relacionado à localização de Anápolis refere-se a sua proximidade à capital do Estado de Goiás, Goiânia, e à capital federal, Brasília, os dois principais eixos urbanos do Centro-Oeste, com destaque para circulação de pessoas e capital. Próximo à Anápolis também se situa a cidade de Pirenópolis (GO), que juntamente com Goiânia integra o Projeto Destinos Indutores do Desenvolvimento Turístico Regional do Ministério do Turismo (Brasil, 2007).

Os aspectos apresentados evidenciam o potencial de Anápolis como centro de crescente fluxo de mercadorias, pessoas e informações. É nesse contexto que o presente artigo destaca que Anápolis não pode ficar ausente de projetos e programas que possam aproveitar essa dinâmica econômico-social como forma de promover elementos locais como atrativos turísticos, considerando potencialidades diversas, o que implica diretamente no investimento na oferta turística. 
É importante realçar, conforme elucidam Ruschmann (1997), Sancho (2001), Boullón (2002), Beni (2003), Cruz (2003), Oliveira e Romero (2015) e Godinho (2019), que a oferta turística implica a existência de um conjunto de objetos técnicos que funcionam de maneira integrada tendo como finalidade promover e subsidiar o uso turístico do espaço geográfico, portanto, o estabelecimento de uma relação de consumo entre turistas e os elementos que constituem determinada configuração territorial, que tem a prática social e atividade econômica do turismo como fator de destaque em sua produção. Dentre esses objetos técnicos dar-se-á ênfase à infraestrutura de hospedagem, pois são equipamentos basilares que subsidiam o uso turístico, visto que o próprio conceito de turismo delineado pela Organização Mundial do Turismo (OMT) implica a estadia de pelo menos uma noite no local de destino (Sancho, 2001).

Diante do exposto, o presente artigo apresenta a cartografia da oferta de hospedagem de Anápolis, tendo como principal objetivo a análise da distribuição espacial e da qualificação da oferta de hospedagem de Anápolis, contemplando a identificação dos objetos técnicos que compõem os meios de hospedagem e a participação das diferentes categorias na oferta de hospedagem.

\section{A OFERTA DE HOSPEDAGEM E SUA IMPORTÂNCIA PARA}

\section{DESENVOLVIMENTO TURÍSTICO}

A Organização Mundial do Turismo define oferta turística como "o conjunto de produtos turísticos e serviços postos à disposição do usuário turístico num determinado destino, para seu desfrute e consumo" (Sancho, 2001, p. 43), e apresenta que os gastos turísticos, ou seja, os gastos com produtos e serviços efetivados pelos turistas funcionam como parâmetro para identificação dos componentes da oferta turística.

Beni (2003) define oferta turística com ênfase na análise econômica do turismo, com isso apresenta duas vertentes para sua compreensão, definidas como oferta original e oferta agregada. Ele afirma que a oferta original se refere aos atrativos turísticos, dados por ele como principal componente do processo produtivo, sem o qual não se pode desenvolver a atividade turística. A oferta original são os elementos turísticos primários de um país, são atrativos que despertam interesse nas pessoas e as levam a dispor de tempo e dinheiro para conhecê-los e experimentá-los, constitui-se como oferta econômica ou bem econômico.

A oferta agregada, conforme Beni (2003), alude ao "conjunto das prestações de serviços das empresas de turismo" (p. 161). Isto é, são os serviços prestados ao turista que os 
auxiliam a usufruir dos atrativos turísticos, referem-se à infraestrutura de hospedagem, transportes, infraestrutura alimentícia, guia turístico, entre outros serviços. O autor argumenta que é necessária a combinação de fatores das vertentes citadas para uma satisfação da demanda turística.

Em consonância com Sancho (2001) e Beni (2003), Ruschmann (1997) afirma que "a oferta turística de uma localidade é constituída da soma de todos os produtos e serviços adquiridos ou consumidos pelo turista durante a sua estada em uma destinação" (p. 138). Portanto, a autora argumenta que o produto turístico são as atrações do núcleo receptor (o fator motivador do deslocamento das pessoas), conjunto de serviços que permitem a permanência das pessoas nas proximidades do atrativo e sua exploração econômica, bem como e as vias e meios de acesso.

Ruschmann (1997) explica que os serviços disponíveis nos espaços de uso turísticos podem ser caracterizados como oferta técnica específica e oferta geral. A oferta específica refere-se aos serviços e equipamentos destinados ao turista, também identificada como infraestrutura turística. Já a oferta geral refere-se ao conjunto de serviços que atendem a totalidade da população local (infraestrutura local), todavia, também é utilizada pelo turista. A autora ressalta que dependendo da qualidade e preço dos serviços, os turistas permanecem mais ou menos tempo no destino turístico, portanto, são elementos que podem potencializar ou limitar o desenvolvimento do turismo.

Desse modo, evidencia-se que a oferta turística abrange uma amplitude de objetos espaciais, dentre os quais os atrativos e infraestrutura turística, somados a presença do turista caracterizam os espaços de uso turístico.

Dentre os componentes da infraestrutura turística, os alojamentos ou infraestrutura de hospedagem permitem a estadia das pessoas no destino turístico, embora não gerem o fluxo de turista são fundamentais para a permanência do turista. Todavia, Godinho (2019) ressalva que na forma de resorts, ao incluírem em sua estrutura um conjunto de atrações, os alojamentos podem se configurar também como atrativos turísticos.

Pode-se afirmar que existe uma relação dialética entre atrativos e a infraestrutura de hospedagem, visto que o desenvolvimento da atividade turística implica o uso dos atrativos turísticos subsidiados pela possibilidade de pernoite em determinado destino turístico, por outro lado, o incremento da hospedagem vincula-se a ampliação da demanda que o turismo pode impor. Essa intrínseca relação justifica a necessidade de estudos quanto à oferta de hospedagem, cuja ênfase nesse artigo se dá em relação à distribuição espacial e a qualificação dos meios de hospedagem de Anápolis. 
O Ministério do Turismo, em parceria com o Instituto Nacional de Metrologia, Qualidade e Tecnologia (INMETRO), a Sociedade Brasileira de Metrologia e a sociedade civil organizada, desenvolveu um Sistema Brasileiro de Classificação de Meios de Hospedagem (SBClass) a fim de favorecer a identificação e qualificação das diversas opções de hospedagem no país, assim estabelecer um panorama geral sobre os meios de hospedagem que compõem a oferta turística nacional. Desse modo, pode-se favorecer o planejamento e gestão de diversos aspectos relacionados à oferta de hospedagem, além de oferecer referencias para que os(as) turistas façam uma escolha adequada às suas expectativas. As informações sobre o SBClass estão disponíveis por meio das Cartilhas de Orientações Básicas do Ministério do Turismo (Brasil, 2010).

Para fundamentar a classificação dos estabelecimentos que ofertam hospedagem, as Cartilhas pautam-se no conceito de meios de hospedagem definido pela Lei $\mathrm{n}^{\circ} 11.771$, de 17 de setembro de 2008, a qual dispõe sobre a Política Nacional de Turismo. Perante o exposto, os meios de hospedagem são:

\footnotetext{
Os empreendimentos ou estabelecimentos, independentemente de sua forma de constituição, destinados a prestar serviços de alojamento temporário, ofertados em unidades de frequência individual e de uso exclusivo do hóspede, bem como outros serviços necessários aos usuários, denominados de serviços de hospedagem, mediante adoção de instrumento contratual, tácito ou expresso, e cobrança de diária (Brasil, 2008, Art. 31).
}

Evidencia-se que estão inerentes ao conceito de meios de hospedagem diversos tipos de estabelecimentos, os quais são classificados no SBClass em sete categorias, considerando um conjunto de características específicas. As categorias do SBClass são: hotel, resort, hotel fazenda, cama e café, hotel histórico, pousada e flat/hotel-apart.

A partir da categorização dos meios de hospedagem é possível traçar um diagnóstico da oferta de hospedagem das cidades brasileiras considerando as características específicas dos estabelecimentos, portanto, obter um conhecimento fundamental para definir estratégias de promoção do turismo que levem em conta projetos e ações para qualificação dos meios de hospedagem, e assim estruturar esse componente da oferta turística de maneira coerente com as demandas turísticas. 


\section{METODOLOGIA}

O desenvolvimento do trabalhou baseou-se inicialmente na composição do inventário da infraestrutura de hospedagem de Anápolis, o que embasou a elaboração dos mapas temáticos sobre a oferta de hospedagem da cidade. Utilizou-se como base de dados o Censo Hoteleiro de Anápolis, de 2018, disponibilizado pelo Observatório do Turismo de Goiás vinculado à Agência Estadual de Turismo do Estado de Goiás (Goiás Turismo). Por meio da diretora do Observatório do Turismo de Goiás, Profa. Giovanna Tavares, adquiriu-se um arquivo em formato xlsx, próprio do editor de planilhas Microsoft Office Excel, que contém os seguintes dados relativos à hospedagem em Anápolis: nome do estabelecimento, nome do proprietário, endereço, telefone, número de leitos e de quartos, tipos de meios de hospedagens (categoriais), qualificação dos meios de hospedagem, entre outras informações que não são necessárias citar visto que não comtemplam o universo do presente artigo.

Observa-se que no Censo Hoteleiro de Anápolis não consta as coordenadas geográficas dos estabelecimentos, elemento fundamental para elaboração cartográfica. Assim, foi necessário realizar o georreferenciamento dos estabelecimentos, procedimento que foi efetivado por meio do Google Maps da empresa Google, que se trata de uma ferramenta para visualização e uso de diversos conteúdos georreferenciados, associados a dados topográficos, imagens de satélites, fotografias, trânsito, informações sobre empresas e serviços, entre outros, ou seja, diversos conteúdos fornecidos pela Google e as empresas vinculadas, e os (as) usuários (as) (Google, 2020).

O georreferenciamento por meio do Google Maps foi realizado utilizando-se como referência os endereços dos estabelecimentos, disponibilizados nos dados do Censo Hoteleiro de Anápolis, de 2018. Assim, no campo de busca do Google Maps inseriu-se o endereço de cada componente da infraestrutura de hospedagem, com isso o Google já identifica a localização específica do empreendimento. Destarte, a escala de visualização do mapa do Google Maps foi ampliada até cinco metros de distância para a compilação das coordenadas geográficas específicas em formato graus decimais, as quais passaram a compor a base de dados da pesquisa. Nota-se que durante a busca, muitos estabelecimentos já constavam registrados na plataforma do Google, o que facilitou o georreferenciamento.

A elaboração cartográfica foi realizada por meio do sistema de informação geográfica (SIG), mais precisamente o software ArcGIS 10.2.2, o que subsidiou a visualização, cruzamento, tratamento dos dados e a elaboração dos mapas da oferta de hospedagem. Foram compilados dados georreferenciados, em formato shapefiles, do Instituto Brasileiro de 
Geografia e Estatística (IBGE), por meio da Diretoria de Geociências. Utilizou-se dados vetoriais relativos à hidrografia (drenagem), à área rural e área urbana (relativo aos setores censitários do estado de Goiás - 52SEE250GC_SIR), e aos logradouros (malha viária urbana/ruas). O shapefile concernente à hidrografia integra à chamada Base Cartográfica Contínua do Brasil, elaborada na escala de 1:250.000 em 2017 pelo IBGE, tendo como sistema de referência geodésica o Sistema de Referência Geocêntrico para as Américas (SIRGAS-2000) ${ }^{1}$. Já o arquivo relativo aos logradouros integra a base do IBGE denominada de Base de Faces de Logradouros, que juntamente com os arquivos área urbana e área urbana fazem parte da Base territorial do Censo Demográfico de 2010. De modo que ambos os arquivos estão associados ao SIRGAS-2000, sendo gerados em uma escala que varia entre 1:2.000 e 1:15.000 dependendo do setor censitário.

Perante a descrição apresentada, elaborou-se um banco de dados cartográficos com o conjunto de arquivos vetoriais (shapefiles) constituintes da base dos mapas, e também com os dados georreferenciados relativos aos meios de hospedagem. Procedimento descritivoanalítico que subsidiou a realização do tratamento gráfico dos dados e a definição dos parâmetros para a elaboração de uma cartografia da oferta de hospedagem de Anápolis, estabelecendo os devidos recortes temáticos, espacial e temporal de cada mapa.

Com base na discussão teórica, no tratamento dos dados levantados e informações reveladas mediante a leitura, análise e interpretação dos mapas temáticos, foi realizado a análise da distribuição espacial e da qualificação da infraestrutura de hospedagem de Anápolis.

\section{CARACTERIZAÇÃO DA OFERTA DE HOSPEDAGEM EM ANÁPOLIS}

Considerando o contexto da cidade de Anápolis, recorte espacial desse artigo, os dados do Observatório do Turismo de Goiás (2018), dispostos na figura 1 demonstram que Anápolis conta com 27 estabelecimentos que se constituem como meios de hospedagem, os quais se dividem em três categorias: Hotéis, Pousadas e Flat/Apart-hotel.

\footnotetext{
${ }^{1}$ O SIRGAS é o Sistema de Referência Geocêntrico para as Américas. Sua definição é idêntica a do Sistema de Referência Terrestre Internacional (ITRS: International Terrestrial Reference System) e sua realização é uma densificação regional da realização do ITRS (ITRF: International Terrestrial Reference Frame) na América Latina. Recuperado de http://www.sirgas.org/pt/about/
} 


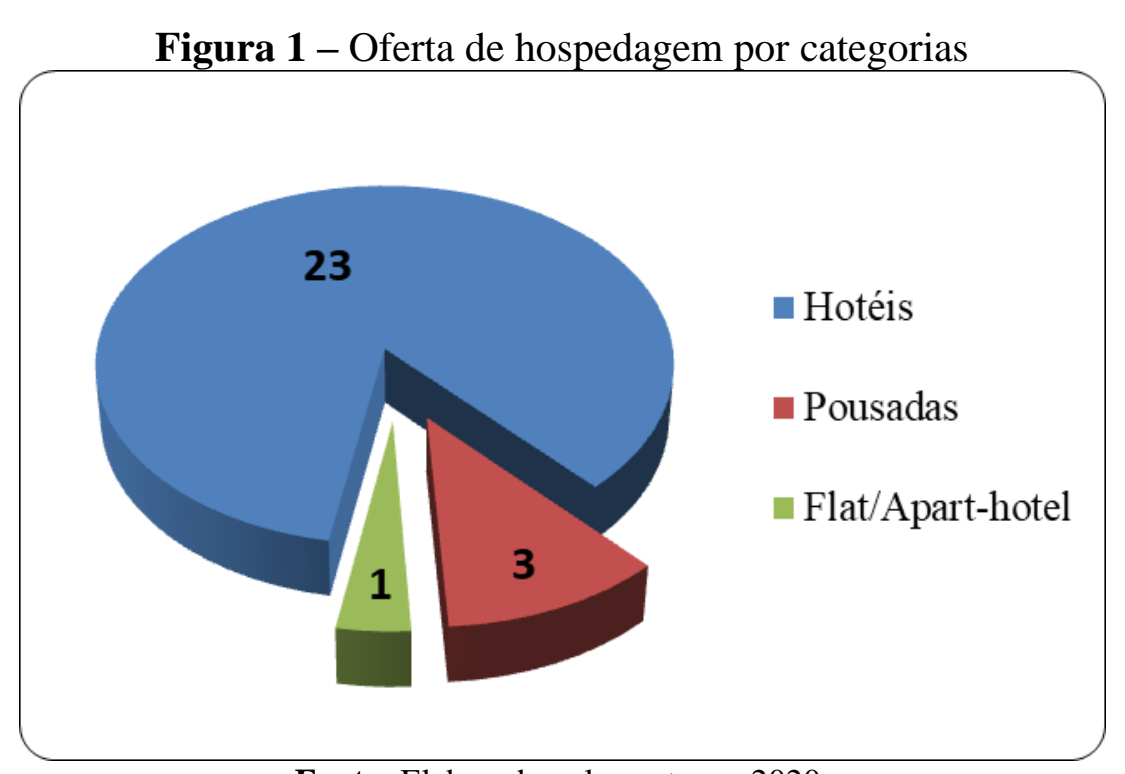

Fonte: Elaborado pelos autores, 2020.

A figura 1 ilustra que não há grande divergência da oferta de hospedagem em Anápolis, pois das sete categorias possíveis de meios de hospedagem apresentadas no SBClass na cidade há apenas três, e dentre elas quase toda a oferta é caracterizada como hotéis, que corresponde a cerca de $85 \%$ da infraestrutura de hospedagem.

Consequentemente, do ponto de vista da oferta de quartos e leitos, em Anápolis também há destaque para os hotéis. Com base nas figuras 2 e 3 observa-se que os números relativos aos hotéis se sobressaem em relação aos demais tipos de estabelecimentos, de tal modo que cerca de $93 \%$ dos quartos e $92 \%$ dos leitos disponíveis aos turistas são ofertados pelos diversos hotéis presentes na cidade. Ainda em relação ao número de quartos e leitos elucida-se que o único flat/apart-hotel da cidade oferece quase a mesma quantidade de quartos e leitos que as três pousadas de Anápolis, a diferença na oferta entre essas duas tipologias de estabelecimento é de menos de $1 \%$.

Destaca-se que na base de dados disponibilizada pelo Observatório do Turismo de Goiás não contemplava informações sobre o número de leitos de um dos estabelecimentos, portanto, estabeleceu-se um contato direto com o empreendimento para completar os dados. Assim, no dia 20 de abril de 2020 efetuou-se uma ligação ao estabelecimento e conseguiu-se a informação que faltava junto ao funcionário da recepção, o qual forneceu a informação com respeito e cortesia, não apresentando nenhum empecilho. 
Figura 2 - Número de quartos por categoria de hospedagem

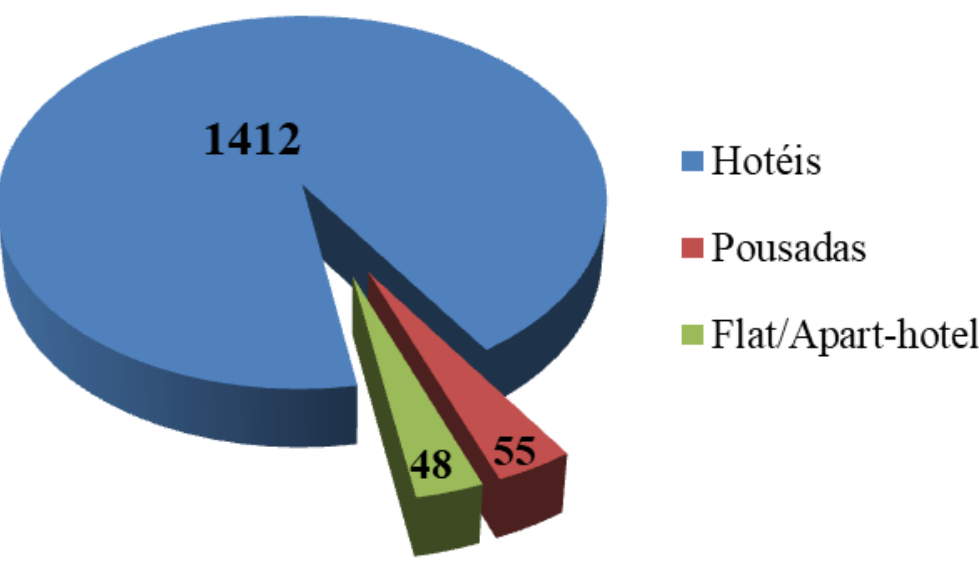

Fonte: Elaborado pelos autores, 2020.

Figura 3 - Número de leitos por categoria de hospedagem

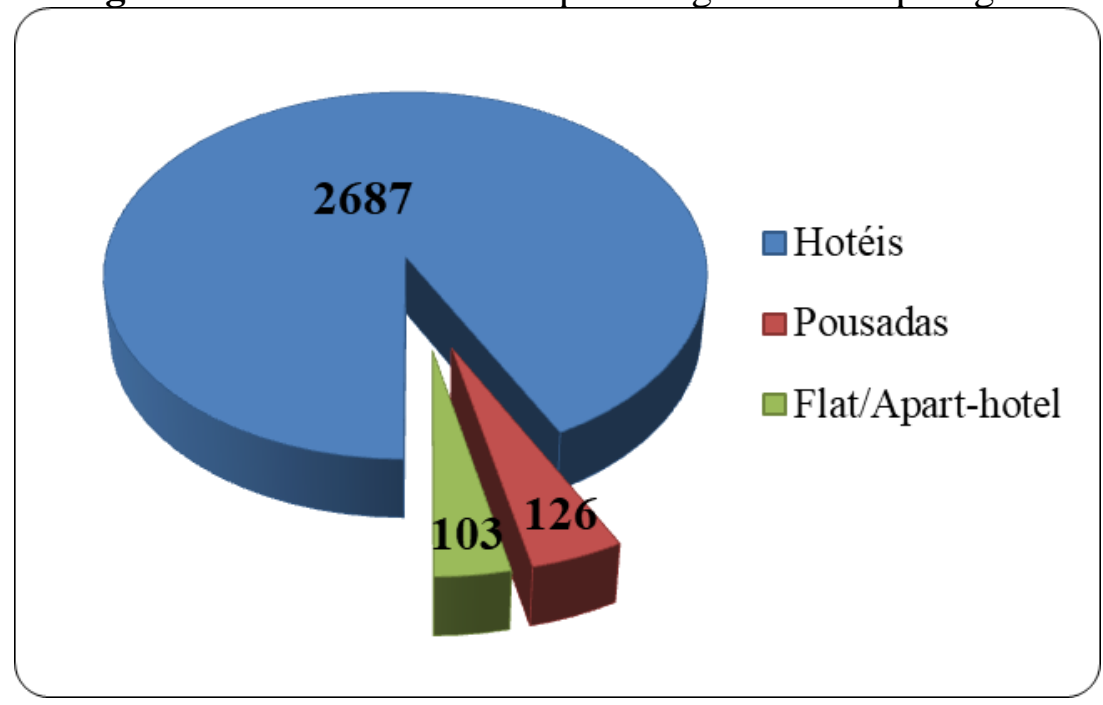

Fonte: Elaborado pelos autores, 2020.

Em relação à qualificação dos meios de hospedagem, no Censo Hoteleiro de Anápolis consta a qualificação de cada estabelecimento conforme as diretrizes do Ministério do Turismo, sendo a base para a análise aqui empreendida.

Evidencia-se que os critérios para qualificação da infraestrutura de hospedagem também são apresentados nas Cartilhas de Orientações Básicas do Ministério do Turismo (Brasil, 2010). Nesses documentos constam parâmetros que permitem atribuir valoração diferenciada aos empreendimentos, a qual é expressa em número de estrelas. Com isso, os estabelecimentos podem receber de uma a cinco estrelas, segundo a avaliação de aspectos específicos de cada tipologia de hospedagem que contemplam três dimensões principais: infraestrutura, serviços e sustentabilidade. A partir da análise dos meios de hospedagem pelo Ministério do Turismo o nível de qualificação é expresso a partir da seguinte classificação, 
considerando do menos qualificado ao mais bem avaliado: simples, econômico, turístico, superior e luxo. Ressalta-se que as estrelas apresentam correlação com a classificação dos estabelecimentos quanto menos estrelas são atribuídas ao um empreendimento menos qualificado ele é. De modo que a um estabelecimento classificado como simples é atribuído uma estrela e a outro, classificado como luxo, cinco estrelas.

Perante o exposto, a tabela 01 demonstra o nível de qualificação da infraestrutura de hospedagem localizada em Anápolis.

Tabela 1 - Qualificação das categorias de hospedagens Anápolis

\begin{tabular}{c|c|c|c|c}
\hline Qualificação & Hotéis & Pousadas & Flat/Apart-hotel & TOTAL (\%) \\
\hline $\mathbf{1}$ estrela & 17 & 3 & --- & $\mathbf{7 4 , 1 \%}$ \\
\hline $\mathbf{2}$ estrelas & 2 & --- & --- & $\mathbf{7 , 4 \%}$ \\
\hline $\mathbf{3}$ estrelas & 2 & --- & 1 & $\mathbf{1 1 , 1 \%}$ \\
\hline $\mathbf{4}$ estrelas & 1 & --- & --- & $\mathbf{3 , 7 \%}$ \\
\hline $\mathbf{5}$ estrelas & 1 & --- & --- & $\mathbf{3 , 7 \%}$ \\
\hline
\end{tabular}

Fonte: Goias. Agência Estadual de Turismo - Goiás Turismo. Observatório do Turismo de Goiás, 2018.

Os dados indicam que os meios de hospedagem que compõem oferta anapolina são, em sua maioria, de baixa qualificação, pois mais de $81 \%$ dos estabelecimentos estão nas classes de uma ou duas estrelas, enquanto apenas cerca de $9 \%$ integram os mais elevados (de três a cinco estrelas). Todavia, o cruzamento dos dados de qualificação com os da oferta de quartos e leitos demonstra que os estabelecimentos mais bem avaliados correspondem à aproximadamente $35 \%$ das vagas de leitos e $28 \%$ do número de quartos, isso revela que há uma considerável disponibilidade de vagas em empreendimentos com maior valoração, embora haja necessidade de investimentos na qualificação do setor para o incremento das atividades turísticas, já que a qualidade dos meios de hospedagem favorece que o turista tenha uma estadia mais curta ou estendida no destino turístico.

\section{MAPEAMENTO E ANÁLISE DA DISTRIBUIÇÃO ESPACIAL DOS MEIOS DE}

\section{HOSPEDAGEM}

As representações cartográficas da oferta de hospedagem de Anápolis foram elaboradas a partir de um caminho metodológico concernente à Cartografia turística, a qual se configura como um campo específico da Cartografia temática que enfatiza a representação cartográfica de espaços de uso turístico. Portanto, fundamenta-se nos postulados da 
Semiologia Gráfica, que por sua vez vincula-se aos conhecimentos no campo da percepção visual definidos pela Gestalt. Para maior compreensão dos fundamentos da Cartografia temática e sua relação com a Semiologia Gráfica e a Gestalt, como citado em Bertin (1988), Joly (1990) e Martinelli (2011).

Do ponto de vista do instrumental técnico para elaboração cartográfica, há de se evidenciar a importância do geoprocessamento para a composição de um banco de dados georreferenciado e consequente cruzamento de diferentes dados turísticos por meio dos sistemas de informações geográficas (SIG), favorecendo a análise e avaliação da produção do espaço geográfico. Conforme explicam Silva e Zaidan (2004) o "geoprocessamento poder ser definido como uma tecnologia, isto é, um conjunto de conceitos, métodos e técnicas erigido em torno de um instrumental tornado disponível pela engenhosidade humana” (p. 19).

Destaca-se que o geoprocessamento não atua como supressor da criatividade e do poder crítico do pesquisador por necessitar que este tenha domínio teórico, conceitual, metodológico de sua área de investigação, assim, o geoprocessamento se revela como recurso adicional na pesquisa e no tratamento dos dados turísticos geográficos.

Destarte, a elaboração de representações gráficas do espaço de uso turístico prevê a definição dos recortes temático, espacial e temporal inerentes ao trabalho, o que subsidiará a busca e análise dos dados.

No contexto desse artigo, o recorte temático geral dos mapas elaborados refere-se à oferta de hospedagem, sendo o recorte espacial a cidade de Anápolis. Já o recorte temporal foi definido conforme a data de geração dos dados dos meios de hospedagem disponibilizados pelo Observatório do Turismo de Goiás, o ano de 2018.

Com base na definição dos recortes e no tratamento dos dados, identificou-se que a natureza das relações entre os dados sobre a infraestrutura de hospedagem compreende, de modo geral, duas dimensões: qualitativa e quantitativa. Todavia, ressalva-se que somente os dados relativos ao número de leitos e quartos são de natureza quantitativa.

Para elaboração dos mapas sobre a oferta de hospedagem de Anápolis, que contempla diferentes tipologias, qualificação e número de leitos, buscou-se expressar as tipologias de hospedagem por meio de duas variáveis visuais que utilizadas de maneira conjunta exprimi melhor a diferença entre os dados, são elas: as figuras geométricas e cores. Aplicou-se também uma variação da tonalidade das cores (claro para escuro) e a variação dos tamanhos das figuras para expressar a qualificação no contexto de cada equipamento da hospedagem, aspectos que implicam uma relação de ordem entre os elementos espaciais com base na qualificação. 
Elaborou-se também o mapa que representa a participação de cada categoria de hospedagem na oferta de leitos. Com isso, para indicar a quantidade de leitos e estabelecer uma relação de ordem foram utilizadas figuras geométricas proporcionais como variável visual, bem como se utilizou de cores para destacar a diversidade dos dados. Cores similares foram utilizadas nos dois tipos de mapas relativos à hospedagem, no intuito de favorecer a associação entre os elementos expressos nas duas representações gráficas que abordam aspectos diferentes de um mesmo componente da infraestrutura.

Com base no exposto, segue-se a análise da distribuição espacial da oferta de hospedagem de Anápolis, a partir da figura 4, que destaca as diferentes categorias de estabelecimentos, e da figura 5 que realça a espacialidade da oferta de hospedagem, a partir do número de leitos.

A figura 4 revela que os hotéis se sobressaem quanto ao número de estabelecimentos de hospedagem situam-se nas proximidades da área central da cidade e sua dispersão acompanha a principal avenida de Anápolis - a Avenida Brasil. Conforme está evidenciado no mapa os hotéis concentram-se nos seguintes bairros: Setor Central, Jundiaí, Cidade Jardim, Vila Goiás e Vila Santa Maria de Nazareth. Nota-se também que alguns hotéis se distribuem no sentido norte-sul da cidade, especialmente localizados próximo as principais entradas de Anápolis. Outro aspecto a se avaliar é a qualificação, o mapa elucida que a maior parte dos hotéis são classificados com uma estrela, apenas dois empreendimentos apresentam maior qualificação, sendo classificados com quatro e cinco estrelas, respectivamente.

Observa-se também por meio da figura 4 que o único empreendimento caracterizado como Flat/Apart-Hotel, classificado com três estrelas, situa-se afastado dos demais estabelecimentos, estando localizado no bairro Maracanã. Já as pousadas apresentam uma relativa dispersão, visto que duas estão situadas no centro da cidade e uma localiza-se no bairro Jaiara, mais ao noroeste da cidade. Todavia, quanto à qualificação, todas as pousadas estão na classe de uma estrela. 
Figura 4 - Cartografia da oferta de hospedagem de Anápolis - categorias e qualificação

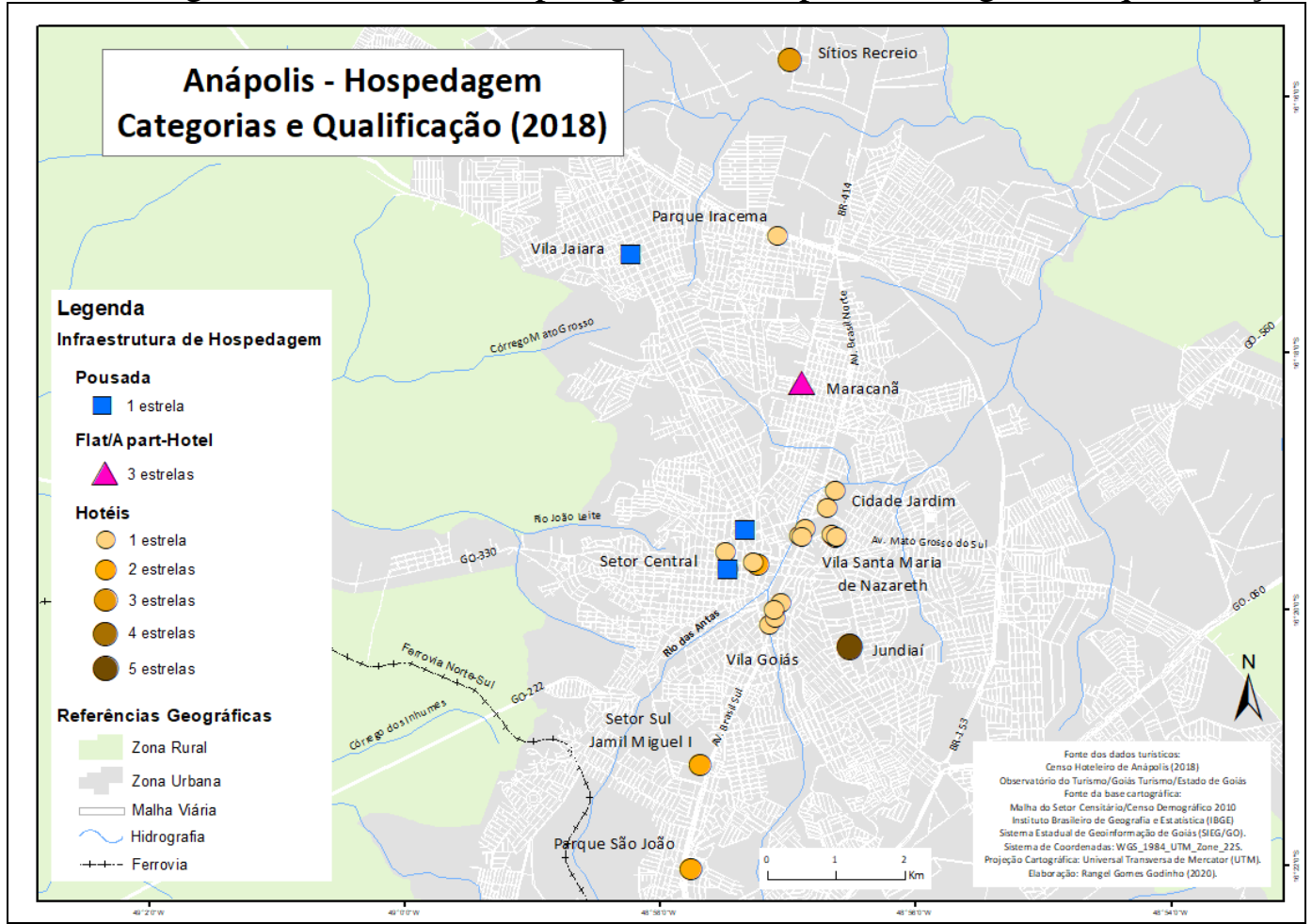

Fonte: Elaborado pelos autores, 2020.

Figura 5 - Cartografia da oferta de hospedagem de Anápolis - número de leitos/categorias

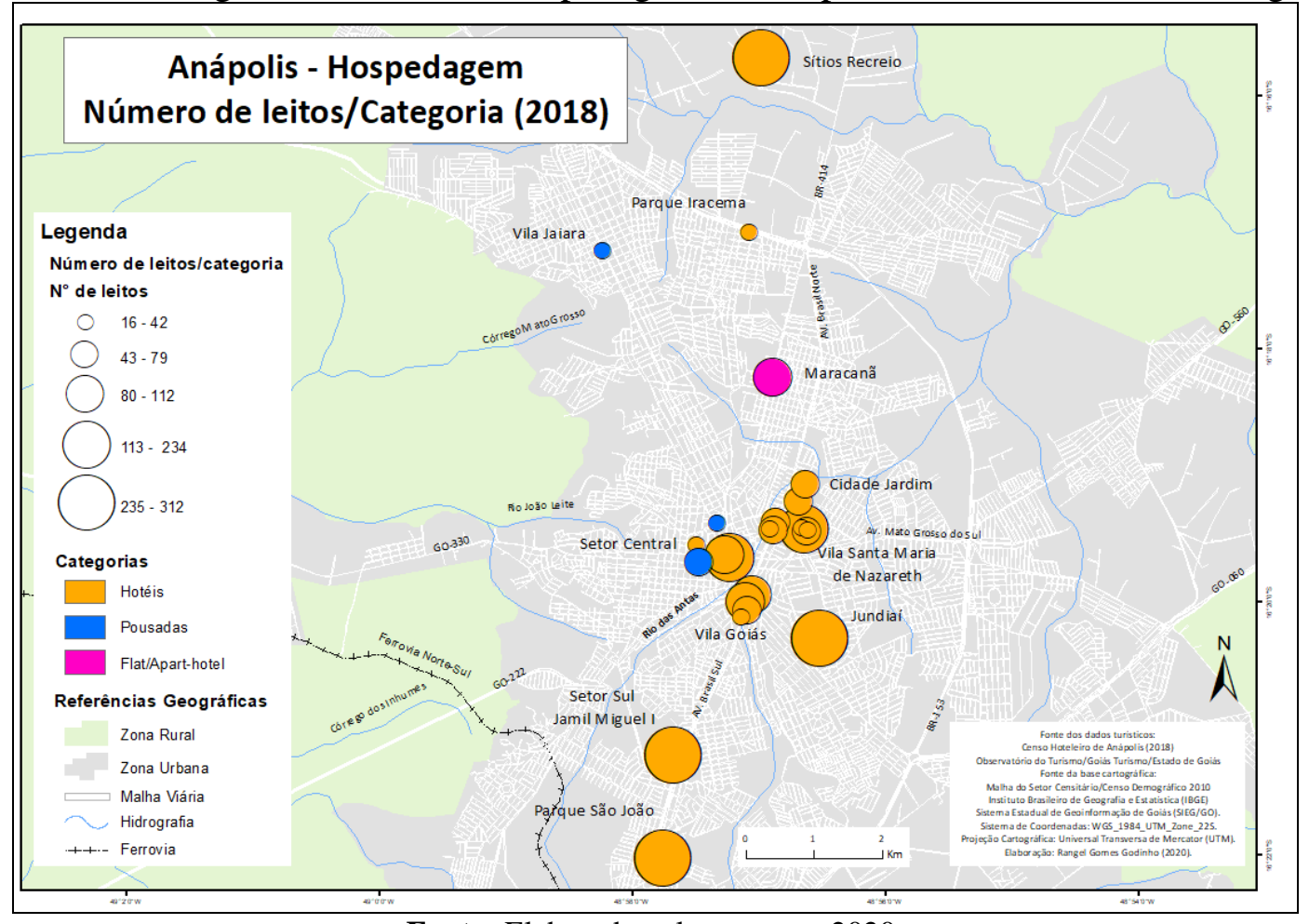

Fonte: Elaborado pelos autores, 2020.

Em relação à oferta de leitos, a figura 5 explicita o predomínio de leitos ofertados pelos hotéis, já o Flat/Apart-Hotel apresenta quase a mesma disponibilidade de leitos que a 
oferta somada das três pousadas, com uma diferença de 23 leitos. O mapa (figura 5) também revela que há um número maior de estabelecimentos que ofertam entre 16 e 79 vagas de leitos, portanto, pequenos empreendimentos.

Ressalta-se que somente a categoria dos hotéis apresenta disponibilidade acima de 113 leitos, dos quais quatro ofertam acima de 235 leitos, ou seja, são os maiores empreendimentos hoteleiros da cidade. Há de se evidenciar que dois desses quatro estabelecimentos são aqueles que apresentam as melhores qualificações (quatro e cinco estrelas).

A análise do mapa sobre as categorias e qualificação da infraestrutura de hospedagem (figura 4) e do mapa sobre a oferta de leitos por categoria de hospedagem (figura 5) permite compreender que há uma concentração dos meios de hospedagem, tanto do ponto de vista espacial, considerando o predomínio de estabelecimentos situados no centro da cidade e adjacências, quanto em relação à categoria e oferta de leitos, visto que os hotéis destacam-se nas duas dimensões.

Perante a análise empreendida, observa-se que a Cartografia, enquanto conjunto de conhecimentos voltados para a construção, uso e interpretação de mapas, que evolui acompanhando o desenvolvimento da humanidade, tem muito a contribuir para a compreensão da produção do espaço uso turístico, pois a informação turística é essencialmente geográfica e pode ser representada cartograficamente (Menezes \& Fernandes, 2003). Associada ao geoprocessamento, a Cartografia revela-se de grande importância, devido à possibilidade de cruzamento de mapas temáticos básicos a partir de sistemas de informações geográficas (SIG), favorecendo a análise e avaliação de diferentes aspectos que compreendem os espaços de uso turístico, dentre eles a infraestrutura de hospedagem.

\section{CONSIDERAÇÕES FINAIS}

Esse trabalho não prevê uma proposta de planejamento turístico, embora os dados e informações geradas possam subsidiar um planejamento consciente da dinâmica do espaço de uso turístico, uma vez que toda a parte analítica da pesquisa também se constitui em mapas temáticos que podem ser insumos para um tratamento de síntese, a partir da análise conjunta de outros elementos que compõem o espaço de uso turístico, chegando ao estabelecimento de um zoneamento turístico, fato que orienta a tomada de decisões quanto ao planejamento turístico.

Anápolis tornou-se uma cidade de destaque com a criação do DAIA e do Porto Seco, fato que realçou as trocas comerciais e o processo de desenvolvimento econômico, elementos 
que implicam o incremento da demanda turística, especialmente o turismo de negócios e eventos. Entretanto, o presente artigo ressalta a necessidade de investimento na oferta turística, em especial quanto à qualificação dos meios de hospedagem. Em relação à oferta de leitos, seria necessário um estudo verticalizado sobre as taxas de ocupação para ter uma análise mais ampla e indicar a necessidade ou não de investir na edificação, ou ampliação, de novos estabelecimentos.

O desenvolvimento da pesquisa mostra que é essencial um planejamento turístico em Anápolis atento à oferta de hospedagem da cidade, no sentido de promover a diversidade de categorias de estabelecimento e qualificação dos empreendimentos.

Conclui-se que a formação do banco de dados georreferenciado e a análise empreendida, além de revelar a importância do desenvolvimento de estudos para os espaços de usos turísticos, fornece subsídios para o delineamento de políticas públicas voltadas ao planejamento e gestão do turismo em Anápolis.

\section{REFERÊNCIAS}

Bertin, J. (1988). Ver ou ler - um novo olhar sobre a cartografia. Tradução de Margarida M. de Andrade. Seleção de Textos, São Paulo, (18), 45- 65.

Brasil. Lei $n^{o} 11.771$, de 17 de setembro de 2008. (2008). Dispõe sobre a Política Nacional de Turismo. Brasília, DF. Recuperado em 04, maio, 2010, de http://www.planalto.gov.br/ccivil_03/_Ato2007-2010/2008/Lei/L11771.htm.

Brasil. Ministério do Turismo. (2007). Estudo de Competitividade dos 65 Destinos Indutores do Desenvolvimento Turístico Regional - Relatório Brasil. Brasília.

Brasil. Ministério do Turismo. (2010). Cartilha de Orientação Básica do Ministério do Turismo. Sistema Brasileiro de Classificação de Meios de Hospedagem (SBClass).

Recuperado em 04, maio, 2020, de http://classificacao.turismo.gov.br/MTURclassificacao/mtur-site/downloadCartilha.action?tipo $=2$

Beni, M. C. (2003). Análise estrutural do turismo. (9a ed.). São Paulo, SP: Senac.

Boullón, R. C. (2002). Planejamento do espaço turístico. Bauru, SP: EDUSC.

Cruz, R. C. A. (2003). Introdução à Geografia do Turismo. (2a ed.). São Paulo, SP: Ed. Roca.

Godinho, R. G., Ferreira, L. C. G., \& Mesquita, P. V. F. (2006) A importância do Porto Seco de Anápolis na economia agroindustrial de Goiás. In: Anais eletrônicos do XIV Seminário de Iniciação Cientifica. CONGRESSO DE PESQUISA, ENSINO E EXTENSÃO DA UFG CONPEEX, 3., 2006, Goiânia.

Godinho, R. G. (2019). Cartografia dos espaços de uso turístico de Trindade, Aparecida e Santiago de Compostela: uma análise comparativa a partir do turismo religioso. Tese de Doutorado. Faculdade de Filosofia, Letras e Ciências Humanas. Universidade de São Paulo, São Paulo, SP, Brasil. 
Google. (2020). Google Maps. Recuperado em 04, junho, 2020, de https://www.google.com/maps/about/

Joly, F. (1990). A cartografia. Campinas, SP: Papirus.

Martinelli, M. (2011). Mapas da Geografia e Cartografia Temática. (6a ed.). São Paulo, SP: Contexto.

Menezes, P. M. L., \& Fernades, M. C. (2003). Cartografia turística: novos conceitos e antigas concepções. In: Anais do XXI CONGRESSO BRASILEIRO DE CARTOGRAFIA. 21, 2003, Belo Horizonte. Belo Horizonte, MG: UFMG, 01-08.

Observatório do Turismo de Goiás. (2018). Censo Hoteleiro Anápolis 2018. Recuperado de http://www.abihgo.org.br/sitewp/wp-content/uploads/2018/11/Censo-Hoteleiro-de-Anapolis2018.pdf

Oliveira, I. J., \& Romero, P. T-de-Z. (2015). Cartografia do turismo em Santiago de Compostela, Espanha. Boletim Goiano de Geografia, 35, 397-416.

Prefeitura de Anápolis. (2020). Economia. Prefeitura de Anápolis, 2020. Recuperado em 04, junho, 2020, de http://www.anapolis.go.gov.br/portal/anapolis/economia/

Ruschmann, D, V. M. (1997). Turismo e planejamento sustentável: a proteção do meio ambiente. (7a ed.). Campinas, SP: Papirus.

Sancho, A. (2001). Introdução ao turismo. Organização Mundial do Turismo - OMT. São Paulo, SP: Roca.

Silva, X., \& Zaidan, R. T. (2004). Geoprocessamento e Análise Ambiental: Aplicações. Rio de Janeiro: Bertrand Brasil.

FORMATO PARA CITAÇÃO DESTE ARTIGO

GODINHO, R. G., PEREIRA, M. E. G., \& COTRIM, L. G. C. V. (2021). Análise da distribuição espacial e qualificação da oferta de hospedagem em Anápolis (Goiás/Brasil). Revista de Turismo Contemporâneo, 9(3), 430-446. https://doi.org/10.21680/2357-

$\underline{8211.2021 v 9 n 3 I D 23811}$ 